\title{
Perancangan Aplikasi Penentuan Bonus Karyawan Dengan Metode TOPSIS
}

\author{
Vibyoa Putri Wijaya ${ }^{1}$, Fitri Marisa ${ }^{2}$ \\ ${ }^{1}$ vibyola.putri@gmail.com, ${ }^{2}$ fitrimarisa@widyagama.ac.id
}

Program Studi Teknik Informatika, Fakultas Teknik, Universitas Widyagama Malang

\begin{abstract}
Intheeraofglobalizationofhumanresources is needed to support every activity. In each company the required employees, therefore one of the drivers of employee performance is to give awards for every job performance achieved by employees. At the company, the determination of employee bonuses is still done manually without any specific criterion to determine the bonus that will be given to each employee. Based on the above problems then the company needs an information system that can help to determine and calculate each criteria in the determination of employee bonuses using TOPSIS method. With the system can helpthe company to determine employee bonuses with precise and accurate.
\end{abstract}

Intisari - Pada era globalisasi sumber daya manusia sangat dibutuhkan untuk menunjangnya setiap aktivitas. Pada setiap perusahaan diperlukannya karyawan, oleh sebab itu salah satu pendorong kinerja karyawan adalah memberikan penghargaan untuk setiap prestasi kerja yang diraih oleh karyawan. Pada beberapa perusahaan, penentuan bonus karyawan masih dilakukan secara manual tanpa ada kriteria khususberdasarkan permalasahan diatas maka memerlukan suatu sistem informasi yang dapat membantu untuk menentukan dan menghitung setiap kriteria dalam penentuan bonus karyawanmenggunakan metode TOPSIS. Dengan adanya sistem tersebut dapat membantu pihak perusahaan untuk menentukan bonus karyawan dengan tepat danakurat.

Kata Kunci - Karyawan, bonus, topsis

\section{PENDAhuluan}

Pada era globalisasi saat ini, kebutuhan akan informasiyang cepat, tepat, dan akurat sangat penting. Segala sesuatunya berubah menjadi praktis namun efisien[1]. Pada saat inibeberapa sistem perusahaan yang berjalan untuk menentukan bonus masih dilakukan secara manual kepadasetiap karyawan yang ada. Dalam upaya untuk mendapatkan data - data yang akurat dengan keadaan karywan disana, maka penyusun melakukan penelitian dan wawancara terhadap beberapa karyawan yang ada. Dari hasil pengamatan yang dilakukan oleh penyusun, maka dapat disimpulkan bahwa karyawan sering merasakan tidak meratanya pembagian bonus setelah pencapaian target yang ada. Dalam upaya peningkatan kualitas pemberian bonus pada setiap karyawan, maka penyusun memberikan saran untuk pemberian bonus menggunakan metode[2].

Untuk mengatasi masalah diatas, maka timbul solusi untuk membuat sistem informasi penentuan bonus karyawan dengan metode TOPSIS. Dengan menggunakan metode tersebutperusahaan dapat menentukan bonus karyawan dengan akuratdan tepat, karena dengan menggunakan metode ini dapatmemprediksi jarak solusi ideal negatif dan positif dari setiapkriteria yang telah ditentukan. Sehingga dapat memudahkanpihak perusahaan untuk menentukan bonus kepada setiapkaryawan dengan tepat dan sangat efisien[3]. Hasil dari penelitianini adalah Nilai prefrensi terbesar diraih oleh karyawanbernama Rino dengan nilai 0,854 kemudian diurutan keduadiduduki oleh Rudi dengan nilai sebesar 0,656, yang ketigadiraih oleh Siswanto nilai preferensi sebesar 0,633, diposisiselanjutnya ada Zaenal dengan nilai 0,307 , dan yang terakhirada ilyas nilai sebesar 0,219. Dari hasil yang diperoleh duakaryawan yang memiliki nilai preferensi terbersar akanmendapatkan bonus berupa umroh, sedangkan karyawan yanglainnya mendapatkan bonus berupa tunjangan tunjangan lain.Penelitian mengenai Sistem Informasi Pemberian BonusKaryawan Dengan Metode TOPSIS berdasarkan eksploitasipenyusun, ditemukan beberapa tulisan yang berkaitan denganpenelitian ini. Penelitian tersebut dari Sariffudin Zulkifli padatahun 2016. Dari penelitian terdahulu hasilnya berupapemberian bonus karyawan yang memiliki nilai preferensidiatas $75 \%$, jika kurang dari presentase tersebut maka karyawan tersebut tidak menerima bonus[4].

\section{TINJAUAN PUSTAKA}

\section{A. Definisi Karyawan}

Karyawan merupakan faktor pendukung dalam sebuah perusahaanatauinstansi,karenadenganadanyakaryawanyang memiliki standar kualifikasi perusahaan maka produktivitas perusahaan pasti akan tetap terjaga dan semakin meningkat. Untuk memperoleh informasi yang cepat dan akurat akan prestasi kinerja karyawan yang tepat (memenuhi kriteria 
yang diharapkan), dibutuhkan suatu proses otomatisasi dengan menggunakan teknologi[4].

\section{B. Bonus}

Bonus adalah imbalan yang diberikan kepada karyawan yang mampu bekerja sedemikian rupa sehingga tingkat produksi yang baku terlampaui [4].

\section{Unified Modeling Language}

UMLadalahbahasapemodelan untuk sistem atau perangkat lunak yang berparadigma berorientasi objek. Dalam $U M L$ terdapat beberapa diagram diantaranya adalah:

\section{Use CaseDiagram}

Diagram usecase tidak menjelaskan secara detail tentang penggunaan usecase, namun hanya memberi gambaransingkat Activity diagram juga dapat menggambarkan proses paralel yangmungkinterjadipadabeberapaeksekusi.Activitydiagram merupakan state diagram khusus, di mana sebagian besar state adalah action dan sebagian besar transisi di-trigger oleh selesainya state sebelumnya (internal processing)[5].

\section{E. TeoriTopsis}

Technique for Order Preference by Similarity to Ideal Solution (TOPSIS) didasarkan pada konsep dimana alternatif terpilih yang terbaik tidak hanya memiliki jarak terpendek dari solusi ideal positif, namun juga memiliki jarak terpanjang dari solusi ideal negatif.

Langkah-langkah penyelesaian masalah MADM dengan TOPSIS [2][3][4]:

1. Membuat matriks keputusan yangternormalisasi.

2. Membuat matriks keputusan yang ternormalisasiterbobot.

3. Menentukan matriks solusi ideal positif \& matriks solusi idealnegatif.

4. Menentukan jarak antara nilai setiap alternatif dengan matriks solusi ideal positif \& matriks solusi idealnegatif.

5. Menentukan nilai preferensi untuk setiapalternatif.

\section{METODE PENELITIAN}

\section{A. Flowchart}

Berikut ini merupakan Flowchart yang akan digunakan dalam penelitian. Tahap pertama yaitu pengumpulan data bisa dilakukan dengan wawancara. Setelah data terkumpuln tahap selanjutnya adalah penentan kriteria dan bobot yang akan digunakandalamprosesperhitunganmetodeTOPSIS,danhasil dari perhitungan tersebut dapat dijadikan suatu rekomendasi perankingan. Adapun flowchartnya sebagi berikut:

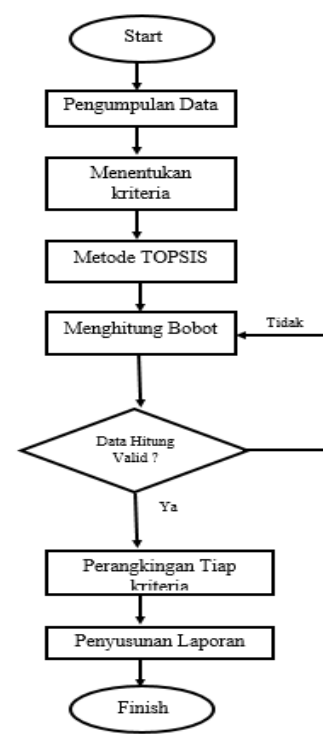

Gambar 1. Flowchart

\section{B. Unified ModelingLanguage}

UnifiedModelingLanguageyangbiasadisebutUMLadalah salahsatubahasapemodelanuntuksistematauperangkatlunak yang berparadigma berorientasi objek. Dalang UML ada beberapamodel,yangpertamaadalahUsecasediagramdimana alur secara umumdijabarkan[5].

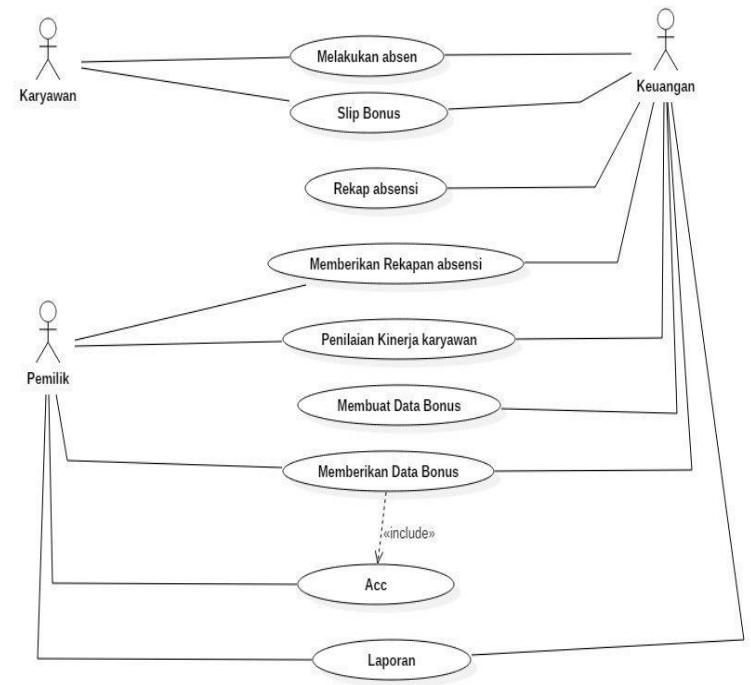

Gambar 2. Usecase Diagram

Dapat dilihat dari gambar 2, untuk aktor karyawan mempunyai tugas hanya absensi dan menerima bonus. Sedangkan aktor keuangan tugasnya antara lain merekap absensi, mengelola data kriteria, dan membuat laporan. Selanjutnya aktor pemilik wewenangnya untuk memberi penilaian terhadap karyawan dan menerima laporan dari keuangan. 
Setelah melalui proses usecase digaram untuk alur lebih detailnyabisadilihatdiActivitydiagramyangmenggambarkan berbagai alir aktivitas dalam sistem yang sedang dirancang, bagaimana masingmasing alir berawal, decision yangmungkin terjadi, dan bagaimana mereka berakhir.

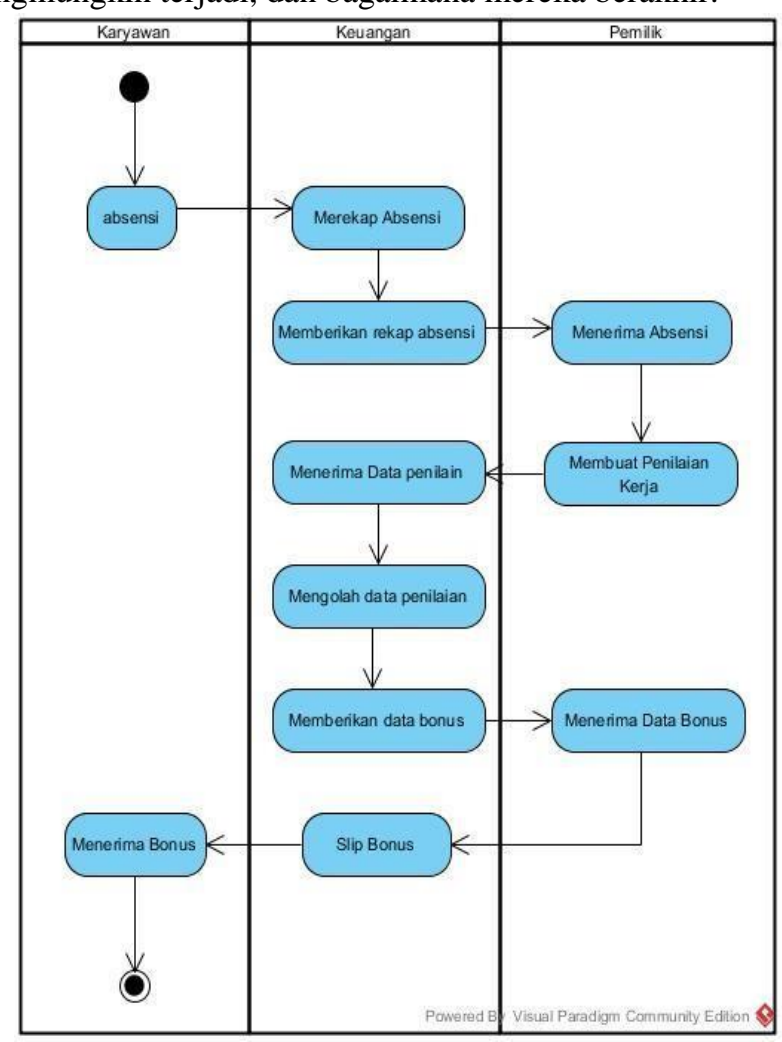

Gambar 3. Activity Diagram

Untuk perancangan databasenya bisa dilihat dari Class Diagram berikut ini :
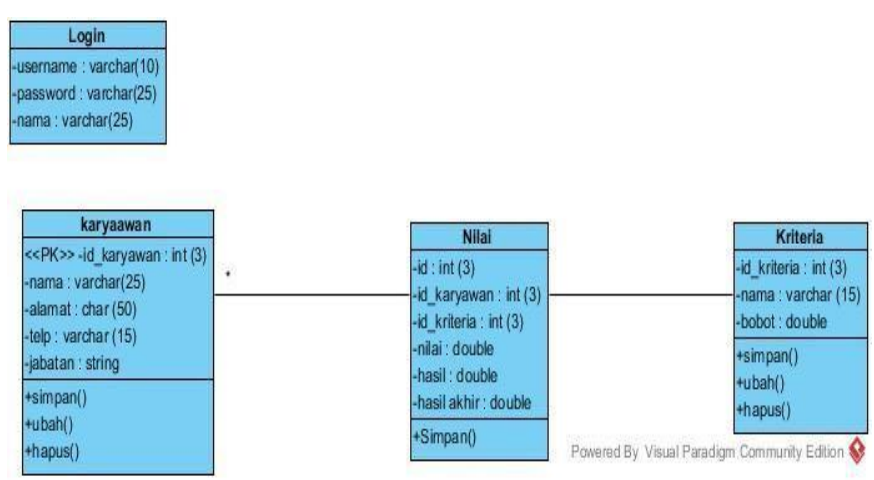

Gambar 4. ClassDiagram

\section{Analisis Data}

Sebagaibahanpertimbanganpenyeleksiandanimplementasi secara manual, maka diambil 5 (lima) karyawan sebagai alternatif seperti ini
Tabel 1. Alternatif Karyawan

\begin{tabular}{|l|l|}
\hline Zaenal & $\mathrm{X} 1$ \\
\hline Rino & $\mathrm{X} 2$ \\
\hline Ilyas & $\mathrm{X} 3$ \\
\hline Rudi & $\mathrm{X} 4$ \\
\hline Siswanto & $\mathrm{X} 5$ \\
\hline
\end{tabular}

Setelah menentukan alternatif karyawan maka dapat diperoleh kriteria dan memberi nilai pada setiap kriteria, sebagai berikut ini :

Tabel 2. Kriteria

\begin{tabular}{|l|l|}
\hline Absensi & C1 \\
\hline Masa Kerja & C2 \\
\hline Loyalitas & C3 \\
\hline Kedisiplinan & C4 \\
\hline
\end{tabular}

Selanjutnya memberi bobot preferensi untuk setiap kriteria yang telah ditentukan.

\begin{tabular}{|l|c|}
\multicolumn{1}{c|}{ Tabel 3.Bobot Preferensi } \\
\hline Absensi & 20 \\
\hline Masa Kerja & 25 \\
\hline Loyalitas & 25 \\
\hline Kedisiplinan & 30 \\
\hline
\end{tabular}

Tahap berikutnya yaitu membuat tabel keputusan. Tabel keputusan tersebut diperoleh dari yang telah terkumpul, maka diperolehnilaiuntukmasingmasing-masingkreiteriadisetaip alternatif yangada.

\begin{tabular}{|l|c|c|c|c|}
\hline Alternatif & C1 & C2 & C3 & C4 \\
\hline Zaenal & 70 & 4 & 70 & 80 \\
\hline Rino & 80 & 10 & 80 & 100 \\
\hline Ilyas & 50 & 3 & 60 & 90 \\
\hline Rudi & 90 & 9 & 50 & 90 \\
\hline Siswanto & 100 & 8 & 70 & 70 \\
\hline
\end{tabular}

\section{HASIL DAN PEMBAHASAN}

\section{A. Hasil NormalisasiTerbobot}

Setelah memberi disetiap kriteria pada alternatif yang ada langkah berikutnya menentukan normalisasi terbobot dengan cara setiap kriteria dikalikan dengan nilai bobot pada setiapkriteria.Berikut ini hasil keputusan normalisasi terbobot: 
Tabel 5. Hasil Matriks Normalisasi Terbobot

\begin{tabular}{|c|c|c|c|c|}
\hline \multirow{2}{*}{ Alternatif } & Absensi & $\begin{array}{c}\text { Masa } \\
\text { Kerja }\end{array}$ & Loyalitas & Kedisiplinan \\
\cline { 2 - 5 } & $\mathbf{C 1}$ & $\mathbf{C 2}$ & $\mathbf{C 3}$ & $\mathbf{C 4}$ \\
\hline X1 & 7,838 & 6,086 & 11,719 & 12,394 \\
\hline X2 & 8,958 & 15,215 & 13,393 & 15,492 \\
\hline X3 & 5,599 & 4,564 & 10,045 & 13,943 \\
\hline X4 & 10,078 & 13,693 & 8,371 & 13,943 \\
\hline X5 & 11,198 & 12,172 & 11,719 & 10,844 \\
\hline Max & 11,198 & 15,215 & 13,393 & 15,492 \\
\hline Min & 5,599 & 4,564 & 8,371 & 10,844 \\
\hline
\end{tabular}

Berdasarkan tabel diatas alternatif $\mathrm{X} 2$ memiliki nilai preferansitertinggiyaitu0,854.MakakarywanatasnamaRino memilik nilai paling tinggi yang mendapatkan bonus berupa umroh, sedangkan karyawan yang lain mendapatkan bonus uang.

\section{KESIMPULAN DAN SARAN}

Dengan adanya system ini perusahaan dapat menentukan dengan jelas kriteria-kriteria beserta bobot kriteria untuk menentukan bonus terhadap karyawan. Nilai preferensi terbesar diraih oleh karyawan bernama Rino dengan nilai 0,854 . Kemudian diurutkan kedua diduduki oleh Rudi dengan nilai sebesar 0,656 , yang ketiga diraih oleh Siswanto nilai preferensi sebesar 0,633,diposisi selanjutnya ada Zaenal dengan nilai 0,307,dan yang terakhir ada Ilyas nilai sebesar 0,219. Dengan menggunakan metode TOPSIS yang diterapkan diperusahaan tersebut dapat memudahkan bagian keuangan dan pemilik perusahaan dalam menentukan karyawan yang berhak mendapatkan bonus secara tepat dan akurat.

Berdasarkan hasil dan kesimpulan tentang perancangan system informasi penentuan bonus karyawan dengan metode TOPSIS, maka saran yang dapat diberikan dalam meningkatkan kualitasnya adalah bagi pengembang berikutnya sebaiknya melakukan penelitian lagi menggunakan metode yang tingkat ke akurasinya lebih baik dan dapat menambahkan kriteria sesuai dengan kebutuhan.

Tabel 6.Hasil Solusi Jarak Ideal Positif

\begin{tabular}{|l|l|}
\hline D1 + & 10,345 \\
\hline D2 + & 2,240 \\
\hline D3 + & 12,585 \\
\hline D4 + & 5,585 \\
\hline D5 + & 5,802 \\
\hline
\end{tabular}

\section{DAFTAR PUSTAKA}

[1] S. Tentang, W. E. B. E. Di, and K. Kota, "e-journal 'Acta Diurna' Volume VI. No. 3. Tahun 2017," vol. VI, no. 3, 2017.

[2] R. Agusli, M. I. Dzulhaq, and U. Khasanah, "Sistem Pendukung Keputusan Pemberian Bonus Tahunan Karyawan Menggunakan Metode TOPSIS," vol. 7, no. 2, pp. 13-21, 2017.

Tabel 7.Hasil Solusi Jarak Ideal Negatif

\begin{tabular}{|l|l|}
\hline D1 - & 4,576 \\
\hline D2 - & 13,097 \\
\hline D3 - & 3,522 \\
\hline D4 - & 10,630 \\
\hline D5 - & 10,021 \\
\hline
\end{tabular}

\section{Hasil Ranking}

Selanjutnya tabel peranking merupakan hasil akhir, peranking diperoleh dengan cara hasil dari solusi jarak ideal negatif dibagi dengan solusi jarak negatif ditambah dengan solusi jarak positif. Maka diperoleh seperti table dibawah ini:

Tabel 8. Hasil Nilai Preferensi

\begin{tabular}{|l|l|}
\hline $\mathrm{X} 1$ & 0,307 \\
\hline $\mathrm{X} 2$ & 0,854 \\
\hline $\mathrm{X} 3$ & 0,219 \\
\hline $\mathrm{X} 4$ & 0,656 \\
\hline $\mathrm{X} 5$ & 0,633 \\
\hline
\end{tabular}

D. Nababan, R. Rahim, F. I. Komputer, U. Pelita, and H. Medan, "SISTEM PENDUKUNG KEPUTUSAN REWARD BONUS KARYAWAN DENGAN METODE TOPSIS," vol. 3, no. 1, pp. 57-62.

B. Karyawan, "Sistem Pendukung Keputusan Penentuan Gaji Bonus Karyawan Pada Restoran KL Express Dengan Metode TOPSIS," vol. 11, no. 1, pp. 101-112, 2017.

M. L. V. R. Vani, M. C. Kumari, M. H. Priya, and N. Harika, "An Effective Language for Object Oriented Design-UML ( Unified Modeling Language )," pp. 1212-1218, 2015. 